\title{
Identification and characterization of a novel bat polyomavirus in Japan
}

\author{
Ryota Koba $^{1} \cdot$ Satori Suzuki ${ }^{1} \cdot$ Go Sato $^{1} \cdot$ Shingo Sato $^{2} \cdot$ Kazuo Suzuki $^{3} \cdot$ Soichi Maruyama ${ }^{2} \cdot$ Yukinobu Tohya $^{1}(\mathbb{C}$
}

Received: 14 April 2020 / Accepted: 13 August 2020 / Published online: 20 August 2020

(c) Springer Science+Business Media, LLC, part of Springer Nature 2020

\begin{abstract}
A novel polyomavirus (PyV) was identified in the intestinal contents of Japanese eastern bent-wing bats (Miniopterus fuliginosus) via metagenomic analysis. We subsequently sequenced the full genome of the virus, which has been tentatively named Miniopterus fuliginosus polyomavirus (MfPyV). The nucleotide sequence identity of the genome with those of other bat PyVs was less than $80 \%$. Phylogenetic analysis revealed that MfPyV belonged to the same cluster as PyVs detected in Miniopterus schreibersii. This study has identified the presence of a novel PyV in Japanese bats and provided genetic information about the virus.
\end{abstract}

Keywords Genetic characterization · Polyomavirus · Bat · Japan

\section{Introduction}

Bats are considered the natural reservoirs of a variety of zoonotic RNA viruses, such as Ebola viruses, Marburg viruses, and severe acute respiratory syndrome coronavirus [1-3]. Several DNA viruses, including adenoviruses, herpesviruses, and polyomaviruses (PyVs), have also been detected [4-6]. However, the pathogenic and zoonotic roles of these DNA viruses have been not clarified.

PyVs are small double-stranded DNA viruses with a circular genome of approximately $5 \mathrm{kbp}$. The viral genome

Edited by Takeshi Noda.

Electronic supplementary material The online version of this article (https://doi.org/10.1007/s11262-020-01789-7) contains supplementary material, which is available to authorized users.

Yukinobu Tohya

tohya.yukinobu@nihon-u.ac.jp

1 Laboratory of Veterinary Microbiology, Department of Veterinary Medicine, College of Bioresource Sciences, Nihon University, 1866 Kameino, Fujisawa, Kanagawa 252-0880, Japan

2 Laboratory of Veterinary Public Health, Department of Veterinary Medicine, College of Bioresource Sciences, Nihon University, 1866 Kameino, Fujisawa, Kanagawa 252-0880, Japan

3 Hikiiwa Park Center, 1629 Inari-cho, Tanabe, Wakayama 646-0051, Japan consists of three regions: regulatory, early, and late regions. The regulatory region is responsible for transcription from both the early and late promoters and the initiation of viral DNA synthesis. The early region contains genes encoding the large $\mathrm{T}$ antigen $(\mathrm{TAg})$ and small $t$ antigen $(\mathrm{tAg})$. The late region contains the structural proteins VP1, VP2, and VP3 [7]. Although PyV diversity in bat populations in North, Central, and South America, Africa, Indonesia, and New Zealand were investigated in previous studies [6, 8-12], the prevalence and genetic diversity of PyVs in Japanese bats remain unclear. The aims of this study were to (i) determine the presence of PyVs in Japanese bats, (ii) characterize the genomic structure of bat PyVs, and (iii) analyze the evolutionary relationships between the bat $\mathrm{PyV}$ detected in this study and other known bat PyVs.

\section{Results and discussion}

Eighteen bats (Miniopterus fuliginosus) were collected in Wakayama Prefecture, Japan. The pooled intestinal contents obtained from each bat (approximately $1 \mathrm{~g} /$ body) were prepared as a $10 \%$ suspension in sterilized phosphate-buffered saline (PBS). The suspension was centrifuged at $17,000 \times g$ for $30 \mathrm{~min}$ at $4{ }^{\circ} \mathrm{C}$. The supernatant was filtered three times through Qualitative Filter Paper Grade I (GE Healthcare, Piscataway, NJ, USA) to remove large debris and then through a $0.45-\mu \mathrm{m}$ bottle top filter (Thermo Scientific, 
Waltham, MA, USA) to remove bacterium-sized debris. The filtrate was centrifuged at $107,000 \times g$ for $3 \mathrm{~h}$ at $4{ }^{\circ} \mathrm{C}$. After the supernatant was removed, the precipitate was suspended after overnight incubation with $500 \mu \mathrm{l}$ of PBS at $4{ }^{\circ} \mathrm{C}$. The enriched fraction containing the predicted viral capsid was obtained via cesium chloride $(\mathrm{CsCl})$ density gradient $(1.7$, $1.5,1.35$, and $1.2 \mathrm{~g} / \mathrm{ml}$ ) centrifugation at $234,000 \times \mathrm{g}$ for $18 \mathrm{~h}$ at $20^{\circ} \mathrm{C}$. Next, the obtained fraction $(1.35-1.5 \mathrm{~g} / \mathrm{ml})$ was diluted tenfold with PBS and centrifuged at $107,000 \times g$ for $3 \mathrm{~h}$ at $4{ }^{\circ} \mathrm{C}$ to remove $\mathrm{CsCl}$. After the supernatant was removed, the precipitate was suspended again in $100 \mu$ l of PBS and treated with Deoxyribonuclease (RT Grade) for Heat Stop (NIPPON GENE, Tokyo, Japan) and RNase ONE (Promega, Madison, WI, USA) to remove any extraviral capsid nucleic acids. DNA extraction was performed using a QIAamp DNA Mini Kit (QIAGEN) according to the manufacturer's instructions. The DNA was then randomly amplified using a Genome Plex Complete Whole Genome Amplification Kit (SIGMA) with random hexamer primers. Amplicons were purified through MobiSpin S-400 columns (MobiTec, Gottingen, Germany). Metagenomic analysis was performed using Illumina HiSeq (Roche, Basel, Switzerland). The genomic data were assembled using GS De Novo Assembler ver. 2.8 computer software (Roche).

A total of 10,136,210 reads and 5362 contigs were obtained in a pool of sample from 18 bats. To identify homologous sequences, the obtained genomic data were analyzed via a BLASTn search using the DNA Data Bank of Japan database in accordance with a previously reported method [13, 14]. Virus-related sequences were identified in 123 contigs. Of these, 14 contigs contained PyV-like sequences with high identities. Other contigs contained the sequences of Eel River basin pequenovirus, Montastraea cavernosa colony-associated virus, and Grapevine-associated totivirus-1. To determine the complete viral genome of these PyV-like sequences, PCR was performed using LA Taq DNA polymerase (Takara Bio, Otsu, Japan) in accordance with the manufacturer's instructions. Specific PCR primers were designed on the basis of the sequences obtained from the contigs. The primer sequences were as follows: Pyv-F1 (sense, 5'-AAG TTT GCA GTA GTC TTT GAA GAT GTG AAG GGT C-3'), Pyv-R1 (antisense, 5'-CAC TCC TGG GCT TTC CTG CTC ATA TTT ATG CA-3'), Pyv-F2 (sense, 5'-CAT AAA CAG GGT CAA ACC AC-3'), and Pyv-R2 (antisense, 5'-AAG CAC TCC ACC AAA GGA AA-3'). DNA extracted from the pooled sample of bat intestinal contents was used as the template. The PCR products were visualized via electrophoresis on a $1 \%$ agarose gel stained with SYBR Safe (Life Technologies, Carlsbad, CA, USA). The full genomic DNA could be amplified by two independent PCR using the aforementioned primers. The amplified DNA was cloned by inserting the PCR product into the pCR2.1 TOPO vector (Life Technologies) in accordance with the manufacturer's instructions. The obtained sequences were analyzed using the BigDye Terminator v3.1 Cycle Sequencing Kit (Life Technologies), and nucleotide sequences were assembled using ATGC computer software (Genetyx Corporation). A homology search was performed using NCBI BLAST.

The genome of Miniopterus fuliginosus polyomavirus (MfPyV) has a length of $4956 \mathrm{bp}$ (accession number: LC529726). The genome organization includes an early region coding for $\mathrm{tAg}$ and $\mathrm{TAg}$ on one strand and a late region encoding the capsid proteins VP1, VP2, and VP3 on the opposite strand. A noncoding regulatory region (NCCR) was located between the start of the early region and that of the late region, in line with previous findings for bat PyVs (Fig. 1a and Supplementary Table 1) [9-12]. Interestingly, open-reading frames encoding VP2 and VP3 of MfPyV did not overlap with that of VP1. The stop codons of VP2 and VP3 are located at base positions 1184-1186, whereas the start codon of VP1 is located at base positions 1188-1190. A single nucleotide (guanine) at 1187 separates the VP2/3 and VP1 regions (Fig. 1a and Supplementary Fig. 1). Therefore, genomic composition of MfPyV is genetically different from those of typical PyVs in terms of non-overlapping $\mathrm{VP}$ regions. Figure $1 \mathrm{~b}$ and $\mathrm{c}$ present the phylogenetic trees of VP1 and TAg of MfPyV and 28 other bat PyVs constructed using neighbor-joining analysis. Based on phylogenetic analyses of the VP1 and TAg amino acid sequences, both regions of $\mathrm{MfPyV}$ are closely related to those of other Miniopterus PyVs and group B bat PyVs (Fig. 1b and c). VP1 is a major $\mathrm{PyV}$ structural protein that is indispensable for entry of the virus into host cells [7]. MfPyV VP1 displayed less than $72 \%$ nucleotide sequence identity with other bat PyVs (Supplementary Table 2). TAg is a multifunctional protein that plays important roles in viral DNA replication and the regulation of viral and cellular gene expression [15-17]. The predicted MfPyV TAg exhibited low similarity $(<73 \%)$ with those of other PyVs (Supplementary Table 2). MfPyV TAg sequences contained features known to be conserved in TAgs of other bat PyVs, including the highly conserved DnaJ domain (HPDKGG), a retinoblastoma ( $\mathrm{Rb}$ )-binding motif (LYCNE), and several functional motifs (Supplementary Fig. 2). According to a previous report, these elements work together to bind $\mathrm{Rb}$ and interrupt its interaction with the E2F transcription factor to promote viral replication and cell cycle progression [18]. TAg is generated via alternative splicing of the early mRNA transcript [11, 19]. In the early region of the MfPyV genome, conserved predicted splice donor sites are located at base positions 4729-4734 (CCTGAG/GTAAGG) and 4346-4351 (TTT CAG/GTCTTC) (Fig. 1a). In the deduced NCCR region of the MfPyV genome, several conserved elements were identified, including several copies of the consensus TAg binding site GAGGC and its reverse complement GCCTC 
A

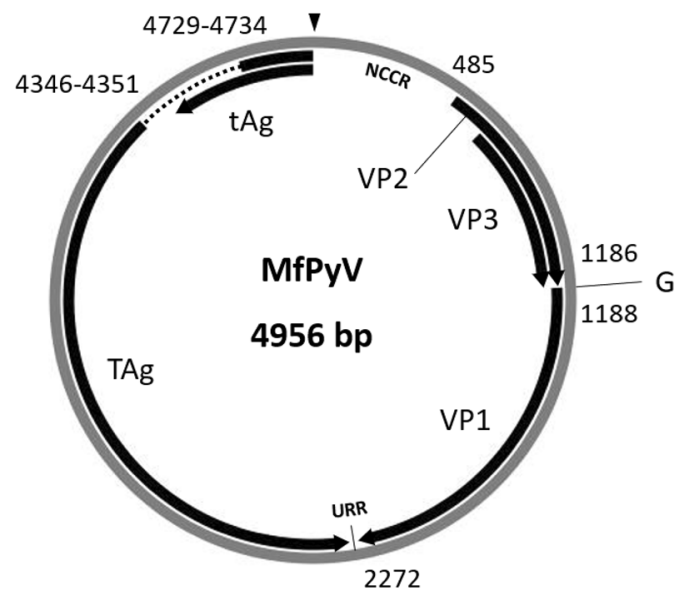

B

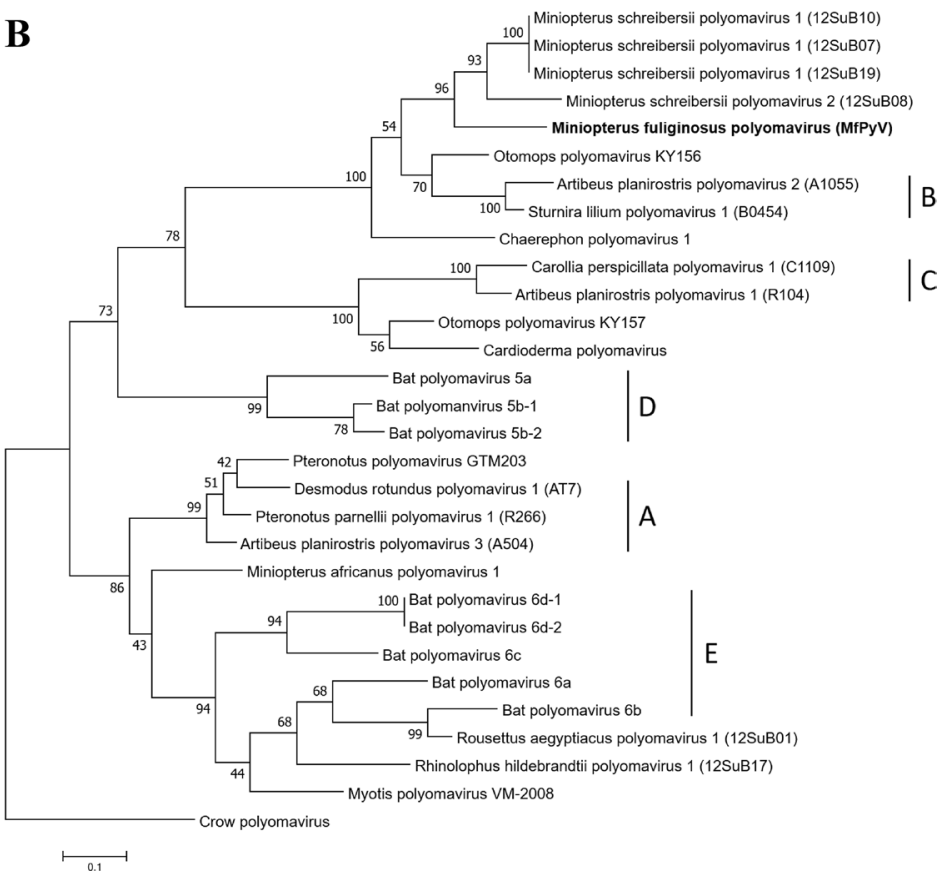

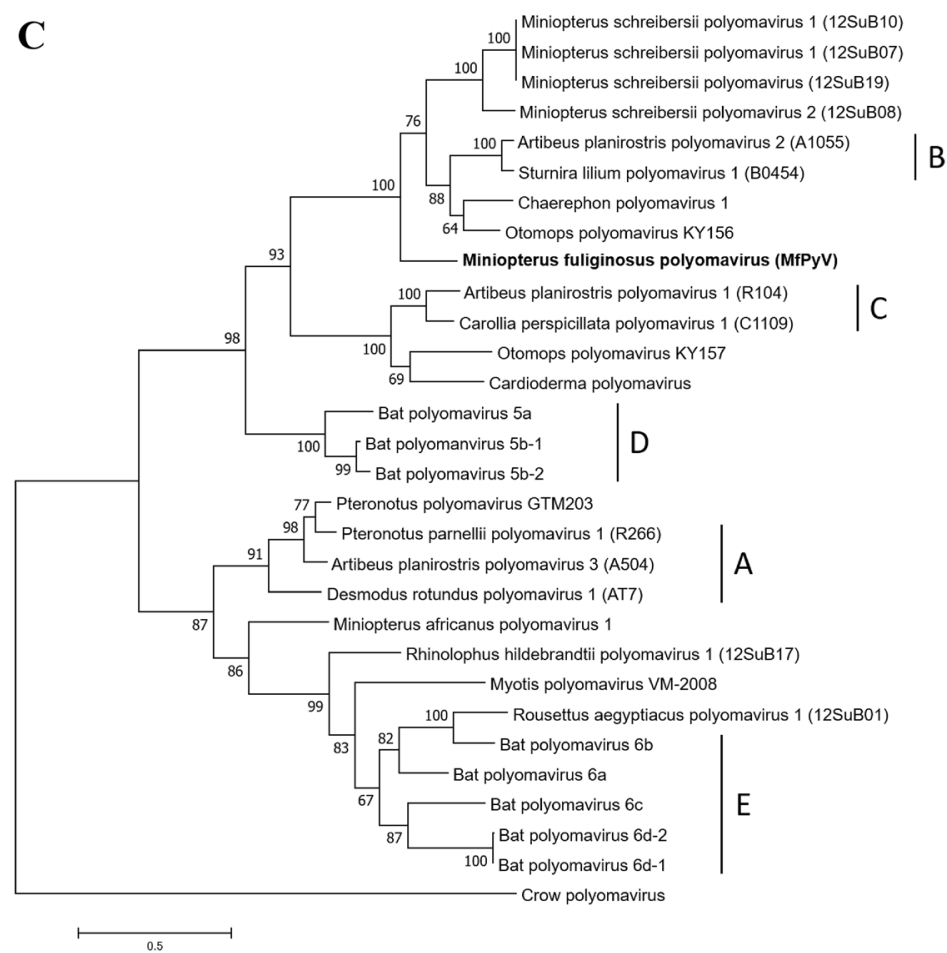

Fig. 1 a Genome organization of Miniopterus fuliginosus polyomavirus (MfPyV). The entire dsDNA viral genome consisted of $4956 \mathrm{bp}$. The viral genome appeared to have a noncoding regulatory region, an upstream regulatory region, potential open-reading frames for the late proteins VP1, VP2, and VP3, and the early proteins small $t$ antigen and large $\mathrm{T}$ antigen (TAg). b and $\mathbf{c}$ Phylogenetic relationships between the amino acid sequences of VP1 (b) and TAg (c) of bat polyomaviruses. MfPyV is indicated by bold text and representative clusters are shown as A-E in the phylogenetic trees. The sequences for the other polyomaviruses were obtained from GenBank. Phylogenetic analysis was performed using the neighbor-joining method with 1000 bootstrap replicates. Bars indicate 0.1 amino acid residue replacements 
(Supplementary Fig. 3). These elements are likely to comprise the core of the replication origin [20].

Comparison of the full-length genome sequence of MfPyV with those of other bat PyVs revealed that MfPyV is most closely related to the KY156 strain with $70 \%$ nucleotide sequence identity (Supplementary Table 2). According to the Polyomaviridae Study Group of the International Committee on Taxonomy of Viruses, a novel PyV species should have $<81 \%$ nucleotide sequence identity to other known PyVs [7]. MfPyV exhibited less than $81 \%$ nucleotide sequence homology to the known reference PyVs including previously reported bat PyVs. In line with the nomenclature of the other bat PyVs, we propose the name MfPyV for the newly discovered virus.

For virus isolation, we attempted to propagate the $\mathrm{MfPyV}$ strain using the Tb1-Lu cell line derived from the lungs of the free-tailed bat Tadaria brasiliensis (ATCC \#CCL-88). However, a cytopathic effect was not observed in the cells following serial passage of the cultures. Viral DNA replication was also not detected in the cells and supernatant collected at each passage. There is a need for additional research to identify efficient cell culture systems for bat PyVs to elucidate the viral infection/replication mechanisms and their pathogenicity.

In conclusion, we detected a novel $\mathrm{PyV}$ genome sequence in Japanese bats. Further epidemiological investigations are needed to determine the extent of PyV genetic variation in various bat species in Japan.

Acknowledgements This study was partly supported by a Grant ("International joint research and training of young researchers for zoonosis control in the globalized world") from the Ministry of Education, Culture, Sports, Science and Technology (MEXT) of Japan.

\section{Compliance with ethical standards}

Conflict of interest There is no conflict of interest associated with this article.

Research involving human participants and/or animals All procedures performed in studies involving animals were in accordance with the ethical standards of the institution or practice at which the studies were conducted.

Informed consent Informed consent is not required because no human participants were involved in this article.

\section{References}

1. Calisher CH, Childs JE, Field HE, Holmes KV, Schountz T (2006) Bats: important reservoir hosts of emerging viruses. Clin Microbiol Rev 19:531-545

2. Hilgenfeld R, Peiris M (2013) From SARS to MERS: 10 years of research on highly pathogenic human coronaviruses. Antivir Res 100:286-295
3. Pourrut X, Souris M, Towner JS, Rollin PE, Nichol ST, Gonzalez JP, Leroy E (2009) Large serological survey showing cocirculation of Ebola and Marburg viruses in Gabonese bat populations, and a high seroprevalence of both viruses in Rousettus aegyptiacus. BMC Infect Dis 9:159

4. Lima FE, Cibulski SP, Elesbao F, Carnieli Junior P, Batista HB, Roehe PM, Franco AC (2013) First detection of adenovirus in the vampire bat (Desmodus rotundus) in Brazil. Virus Genes 47:378-381

5. Zhang H, Todd S, Tachedjian M, Barr JA, Luo M, Yu M, Marsh GA, Crameri G, Wang LF (2012) A novel bat herpesvirus encodes homologues of major histocompatibility complex classes I and II, C-type lectin, and a unique family of immunerelated genes. J Virol 86:8014-8030

6. Tao Y, Shi M, Conrardy C, Kuzmin IV, Recuenco S, Agwanda B, Alvarez DA, Ellison JA, Gilbert AT, Moran D, Niezgoda M, Lindblade KA, Holmes EC, Breiman RF, Rupprecht CE, Tong S (2013) Discovery of diverse polyomaviruses in bats and the evolutionary history of the Polyomaviridae. J Gen Virol 94:738-748

7. Johne R, Buck CB, Allander T, Atwood WJ, Garcea RL, Imperiale MJ, Major EO, Ramqvist T, Norkin LC (2011) Taxonomical developments in the family Polyomaviridae. Arch Virol 156:1627-1634

8. Misra V, Dumonceaux T, Dubois J, Willis C, Nadin-Davis S, Severini A, Wandeler A, Lindsay R, Artsob H (2009) Detection of polyoma and corona viruses in bats of Canada. J Gen Virol 90:2015-2022

9. Fagrouch Z, Sarwari R, Lavergne A, Delaval M, de Thoisy B, Lacoste V, Verschoor EJ (2012) Novel polyomaviruses in South American bats and their relationship to other members of the family Polyomaviridae. J Gen Virol 93:2652-2657

10. Kobayashi S, Sasaki M, Nakao R, Setiyono A, Handharyani E, Orba Y, Rahmadani I, Taha S, Adiani S, Subangkit M, Nakamura I, Kimura T, Sawa H (2015) Detection of novel polyomaviruses in fruit bats in Indonesia. Arch Virol 160:1075-1082

11. de Sales Lima FE, Cibulski SP, Witt AA, Franco AC, Roehe PM (2015) Genomic characterization of two novel polyomaviruses in Brazilian insectivorous bats. Arch Virol 160:1831-1836

12. Wang J, Moore NE, Murray ZL, McInnes K, White DJ, Tompkins DM, Hall RJ (2015) Discovery of novel virus sequences in an isolated and threatened bat species, the New Zealand lesser short-tailed bat (Mystacina tuberculata). J Gen Virol 96:2442-2452

13. Hall J, Wang J, Todd AK, Bissielo AB, Yen S, Strydom H, Moore NE, Ren X, Huang QS, Carter PE, Peacey M (2014) Evaluation of rapid and simple techniques for the enrichment of viruses prior to metagenomic virus discovery. J Virol Methods 195:194-204

14. Shan T, Li L, Simmonds P, Wang C, Moeser A, Delwart E (2011) The fecal virome of pigs on high-density farm. J Virol 85:11697-11708

15. Bargonetti J, Reynisdottir I, Friedman PN, Prives C (1992) Sitespecific binding of wild-type 553 to cellular DNA is inhibited by SV40 T antigen and mutant p53. Genes Dev 6:1886-1898

16. Ahuja D, Saenz-Robles MT, Pipas JM (2005) SV40 large T antigen targets multiple cellular pathways to elicit cellular transformation. Oncogene 24(52):7729-7745

17. Ali SH, DeCaprio JA (2001) Cellular transformation by SV40 large $\mathrm{T}$ antigen: interaction with host proteins. Semin Cancer Biol 11(1):15-23

18. Sullivan CS, Cantalupo P, Pipas JM (2000) The molecular chaperone activity of simian virus 40 large $\mathrm{T}$ antigen is required to disrupt Rb-E2F family complexes by an ATP-dependent mechanism. Mol Cell Biol 20:6233-6243 
19. Huang Y, Carmichael GG (2009) RNA processing in the polyoma virus life cycle. Front Biosci 14:4968-4977

20. Li L, Li BL, Hock M, Wang E, Folk WR (1995) Sequences flanking the pentanucleotide T-antigen binding sites in the polyomavirus core origin help determine selectivity of DNA replication. J Virol 69:7570-7575
Publisher's Note Springer Nature remains neutral with regard to jurisdictional claims in published maps and institutional affiliations. 